\title{
“Language Alludes to Everything": A Pilot Study on Front-Line Worker Experience with Newcomer Integration
}

\author{
Alesia Au¹, Halley Silversides ${ }^{1}$, Katerina Palova ${ }^{1}$, Cesar Suva ${ }^{1}$, and Suzanne Goopy ${ }^{1}$ \\ ${ }^{1}$ University of Calgary, Alberta, Canada \\ DOI: https://doi.org/10.47611/jsr.v10i1.1137
}

\begin{abstract}
$\underline{\text { ABSTRACT }}$
There remains an ongoing need to address not only the post-migration experiences of newcomers settling in Calgary but also to understand how systems that serve them perceive, make sense of, and contribute to these experiences. By hearing from those who work with newcomers within the institutional settings that support newcomers, we can begin to understand some complexities of newcomer integration. The purpose of this qualitative pilot study was to explore the perceptions that front-line workers hold regarding needs and experiences of newcomers. This study involved a series of eleven semi-structured interviews with workers at an immigrant-serving language-learning agency which were analyzed using thematic coding. The findings highlighted: front-line workers perception of their newcomer clients' identity in connection to language; the clients' emotional burden and sense of belonging; and the challenges clients faced balancing everyday commitments. Moreover, this study explored the front-line worker's role in cultural brokerage and promoting wellness. This study provided reason to value the practices and interpretations that frontline workers have of the newcomer experience due to the role they play in creating a sense of integration for newcomers. The interpretations that surfaced in this study sheds light on the complexity that both front-line workers and newcomers face and implies that further research and interventions are needed to ensure successful integration.
\end{abstract}

\section{Introduction}

Successful integration into the host society is the ultimate aim of government supported migration within Canada. Newcomers (referring collectively to those who have been accepted for settlement in Canada irrespective of their initial status as economic migrant, family reunion, or refugee) are supported in their bid for successful integration via a series of language acquisition, settlement, and employment services (Government of Canada, 2020). In this paper we explored the experiences of front-line workers within the service area of language acquisition, and in particular English language acquisition. In doing so, we sought to understand the barriers and facilitators that confront those working with newcomers on language acquisition. We have chosen to focus on those individuals who support clients enrolled in English language acquisition programs (Language Instruction for Newcomers to Canada [LINC] program and English as a Second Language [ESL]) because these present a significant, particular, and intensive relationship between service providers and newcomers.

\section{Background}

Canada remains a longstanding place of settlement entrenched with policy changes to accommodate various populations and global events over time (Edmonston, 2016). In 2015, the Canadian Federal Government established a private sponsorship model which changed the scope of the Canadian system in its ability to accommodate the magnitude of 
persons that required resettlement. Consequently, from November 2015 until February 2017, more than 40,000 Syrians resettled across Canada into over 350 communities (Government of Canada, 2017). \#WelcomeRefugees, the government initiative aimed at publicizing and supporting the large influx of Syrian refugees has also changed the scheme of immigration to Canada. Upon arriving in Canada, immigration offices run by Immigration, Refugees and Citizenship Canada (IRCC) provide specific services related to refugee claims, citizenship endeavors, travel document issuance, and immigration interviews (Government of Canada, 2018). Meanwhile, settlement assistance and integration programs rely heavily on organizations based in the communities in which the immigrants reside, one service being the LINC program that was first established in 1992 (Guo, 2015). Currently, LINC programs use the Canadian Language Benchmarks (CLB) for measuring language proficiency of adult immigrants in English (Government of Canada, 2011). The CLB standard reflects the progression of the knowledge and skills that underlie basic, intermediate and advanced ability. Newcomers are placed in a CLB class appropriate for their level of speaking, listening, reading, and writing abilities. For learners with little or no literacy skills in their own language, Pre-CLB classes, also known as literacy or foundation classes are offered in language learning agencies across Canada (Government of Canada, 2011). While LINC typically operates on a free of charge basis for newcomers as funded by IRCC, ESL functions on a varying fee and attendance basis (Immigrant Services Calgary, 2020). These programs are customized from basic to advanced levels with the option of drop-in-style classes or one-on-one tutorial sessions.

\section{Front-line Workers in Action}

Front-line workers in this paper, refer to those who have direct or close contact with newcomer clients via English acquisition programs and accompanying programs supporting newcomer integration. They include, instructors, program coordinators, receptionists, and supervisors who, due to the nature of the work and the organisational structure, have frequent, continuous contact with newcomer clients for extended periods of time (a typical full-time LINC class met 25 or more hours per week; on average 32.7 weeks in a term) during the early integration period spanning the first six months up to three years (Government of Canada, 2011). This places instructors, support workers and managers in a direct position to engage and enable newcomer integration. However, the potential for role complexity and some role confusion for these front-line workers, particularly instructors, is considerable leading to the potential for actions and attitudes to act as barriers to rather than the intended facilitators of integration (Gardner, 1985).

In any context, knowledge and its sources are multiple in both origin and form. In the case of front-line workers, both formal and informal, tacit and deliberate knowledge will inform decisions (Smith, 2001). Thus, not only the various levels of training staff have but also their own perceptions, memories, reasons, and testimonies will influence how they interact with newcomer clients (Audi, 2002). Despite the intentions of organisations responsible for providing or planning supports and programs, this support may be defined and perceived quite differently by the people both delivering the service and those requiring services (Simich et al., 2005). This may be partially exacerbated by culturally based expectations specific to the newcomer sector alongside how their work is perceived by clients, workers often struggle to adapt to changing work environment and policies. Such struggles include, being underfunded; a confounding sense of accountability for service gaps; and, an ongoing battle with jurisdictions and Canadian cities to create influence on the integration process (Simich et al., 2005; McIsaac, 2003).

As part of the support networks of newcomers, front-line workers will have both shared, and unique interactions with newcomer clients as they seek to integrate into their life in Canada. These workers are often teaching and interacting on-site with clients full-time (on average 25 to 30 hours per week) or part-time (on average 6 to 15 hours per week). Because of the nature of their roles, front-line workers are well-situated to not only deliver language learning to newcomers but also to build rapport, assist them to cope with their new cultural and linguistic environment and in turn appropriate the role of a trustworthy local. In short, the front-line staff are now also cultural brokers (Adkins et al., 1999). Moreover, as language is a living skill, instructors are not only providers of knowledge for language learning purposes, but they inevitably are a part of the social systems into which newcomers integrate (Ho, 1998). One study demonstrates this very clearly highlighting how adult refugee trauma survivors attending ESL classes grew to 
trust and rely on instructors due to the sense of continuity in the instructors' teaching which further enforces the unique connection between front-line staff and newcomers (Finn, 2010).

\section{Newcomer Integrational Challenges}

It is well-established that newcomers to Canada face challenges during the settlement period. The brochure Welcome to Canada: What you should know is provided for newcomers to assist in guiding them through the expectations of what Canadian life will be. The document outlines that within the first two months in Canada, newcomers are expected to begin job searching, plan to improve English or French language skills, search for housing, register children in schooling, learn about education options to improve qualifications, obtain a driver's license if applicable, and find a doctor or health-care centre to receive a medical check-up and vaccination update (Citizenship and Immigration Canada, 2013). However, particular to the economic stability of refugees, mixed success is apparent in relation to employment status and income levels (Wilkinson \& Garcea, 2017). The authors argue that it can take newcomers more than a decade to fully integrate into the labour market and reach the average pace of native-born Canadians. Canadian labour force reports recorded that in contrast to the employment rates of native-born Canadians, there was a 14.2\% difference in employment rates for immigrants landing less than 5 years prior, which narrows to a $2 \%$ difference between immigrants who landed over 10 years prior (Yssaad \& Fields, 2018). This reinforced that the gap between immigrants and native-born Canadians narrows based on the time of landing but does not fully disappear.

Additionally, it is likely that newcomers will experience acculturation in the form of assimilation and marginalization (Berry, 1997). The author reported that these instances occur as a result of lifestyle choices that see newcomers either actively engaging or being unable to actively participate within their host society. In its maladaptive form, "acculturative stress" persists when attempts by newcomers to bridge their personal and cultural sense of belonging become negative, stressful experiences (Adkins et al., 1999). Immigrant health trends are an example of the manifestations of acculturative stress and are arguably manifested in five domains: physical difficulties with migration, biological changes (such as diet changes and exposure to diseases specific to the host country), cultural isolation, social uncertainty and psychological struggle (Berry et al., 1987).

With an estimated population growth of over 340,000 immigrants in 2019, there remains an ongoing need to address the post-migration experience and its impact on the wellness of immigrants who settle in Canada (Statistics Canada, 2020). When choosing a location in which research should take place, it is imperative to consider the context of newcomer influx into a community or city. Research has most commonly been conducted in those cities with the highest influx commonly referred to as "first-tier" cities in Canada (Toronto, Montreal or Vancouver) (Agrawal \& Kurtz, 2019). "Second-tier" cities such as Edmonton, Calgary, Winnipeg and Ottawa are often missing from the research despite being some of the top destinations to receive immigrants who did not arrive in the aforementioned "first-tier" areas. Designation as a "second-tier" city is based on the criterion of taking in 40,000 to 100,000 immigrants over a five-year period. As few studies exist on second-tier cities, there is an opportunity to further research specific to this area.

\section{Method}

\section{Aim}

The aim of this study was to explore front line workers' views of newcomer clients' learning and integration experiences as they present themselves within the delivery of a LINC or ESL program. The objectives of this study were to investigate front-line workers' understanding of newcomer client experiences of participating in learning English, and the barriers and facilitators to this.

\section{Design}

This interpretive study was a small, multi-site pilot study conducted as a summer student project to support the basis for a larger mixed methods study on emotional wellness and LINC service delivery. This study included eleven semi- 
structured interviews with front-line workers. The setting was a well-established multi-site not-for-profit charitable organization that serves the newcomer population in the areas of English language acquisition, employment, and settlement assistance. A single student researcher undertook data collection between June 2018-August 2018.

\section{Participants}

Purposive maximum variation sampling of front-line workers was undertaken. This method of sampling allows the researcher to decide what qualitative information must be collected and use this criterion to find participants who have the capacity or willingness to provide this information whether it be due to their knowledge or experience (Bernard, 2011). Especially in the context of qualitative work and having a small sample size, efforts were made to address all available angles about the issue at hand by finding participants who are willing to communicate about their experiences and opinions reflectively, and to welcome differences in job roles, perspectives and practices (Etikan, Musa, \& Alkassim, 2016). Congruent with Human Research and Ethics requirements, recruitment methods consisted of poster usage, word of mouth, as well as presentation to staff in a General Staff Meeting on-site after which the staff were given the option to take part. Inclusion criteria was assumed for those who self-identified as working first-hand with the newcomer clients. Exclusion criteria was staff who did not work directly with the clients on a daily basis, such as executive management or human-resource staff. Consequently, the sample for this study included instructors, managers, and staff-volunteers who had direct or close contact with newcomer clients via LINC (Literacy and Non-Literacy), ESL, childminding, and counselling/wayfinding. While newcomer students spent their time in the LINC and ESL classes, the childminding program helped with supervising their young children during the hours that they were in class. The counselling programs facilitated as an appointment-based wayfinding service that assisted newcomer students in accessing resources and supports in their community. Those who agreed to participate signed a consent form. All front-line workers who agreed to participate were interviewed.

\section{Data Collection}

A total of eleven semi-structured interviews with front-line staff were conducted, audio-recorded and lasted approximately 60-90 minutes in duration. The interviewer was flexible in the approach, interviewed front-line workers at a time and place of convenience for them. The interview commenced with a pre-written preamble that refreshed participants understanding of the topic of the interview and their requirements. Participants were made comfortable by asking general questions about their day prior to commencing interview questions. A semi-structured interview guide was used to ensure consistency. The following questions are some examples from the guide:

1. What do you perceive as the experiences that newcomers face when managing their wellness when they are settling in Calgary?

2. What experiences would explain the facilitators involved?

3. How do you try to mediate or help the clients work through their experiences? As part of your role? Aside from your role?

These questions were only used as a guide. While using a grounded theory approach, the researcher sought to gain a different perspective on a situation and bring light to uncharted information (Strauss \& Corbin, 1990). This naturalist approach allowed for the broad exploration with the participants of what they see as newcomers' needs, and the reasons they believe the clients have for coming to class or accessing services. This type of inquiry allowed the researchers to study how an issue was displayed in reality and the intention was not to manipulate research variables to foresee a change in outcome (Bowen, 2008). This allowed us to thoroughly explore what the workers have experienced in responding to their work with newcomers. 


\section{Ethical Considerations}

This research study was reviewed and approved by the Conjoint Health Research Ethics Board (CHREB) committee at the University of Calgary. The study was supported by the service delivery site. Participants were provided with a plain language information statement that detailed the study background and their required involvement. Verbal and written explanations were given to participants about the risks and benefits, their rights, how information would be de-identified and how information would be used. All participants were given adequate time to consider their involvement and signed a consent form prior to undertaking interviews.

\section{Data Analysis}

Digital recordings of the interviews were listened to immediately after the interview and a summary was written (Miles et al., 2014). This process enabled common information and gaps in the data to be identified. This knowledge was discussed with the supervisor and used to inform the focus of successive interviews. Interview recordings were transcribed verbatim by the researcher. Analysis was conducted with the researcher's supervisor using clear analytic steps. Iterative, inductive content analysis was performed on transcripts, concurrently with data collection. The researchers initially gained an overall sense of the data by reading and re-reading transcripts (Elo \& Kyngäs, 2008). Line by line coding of the data was conducted and these codes were developed into subcategories and then categories (Elo \& Kyngäs, 2008). On the basis of this, overall agreement that data saturation had occurred was reached and no further interviews were required.

\section{Rigour}

Rigour was upheld using qualitative strategies (Lincoln \& Guba, 1985). A series of reflexive techniques were employed to ensure that researcher experiences did not influence the data. Credibility of the findings was enhanced by the practice of the researchers collectively and individually reflecting on the quality and content of interviews. The research team documented and discussed their preconceptions and ideas throughout the analysis process. Finally, the established themes were presented to participants for member checking. An audit trail of the process was maintained.

\section{Findings}

Several themes and observations emerged from the interviews with the front-line workers: clients' perception of their identity in correlation to language proficiency, the clients' emotional burden related to their sense of belonging, the challenges clients faced balancing multiple commitments, and the front-line worker's own role in cultural brokerage for clients. Participant quotes were left unaltered to the best of our abilities to maintain authenticity, with the exception of some clarifying words to assist with context and comprehension.

\section{Perception of Identity}

Specific to a newcomers' sense of identity, participants spoke to the difficulties they perceived that newcomers experienced in integrating with the mindset of knowing what it meant to be Canadian. Ultimately what it meant to be living in a new context, with new struggles, and most of all with a new language. To highlight this, Participant 4 stated:

"they may not realize how to deal with busy life and stress properly, in a totally different country, totally different language, in a different culture".

All participants indicated that the ability to master the English language was an opportunity for the newcomer clients to have overall better life experiences. To highlight this indication, Participant 7 stated: 
"Not knowing the language alludes to everything... not having a job, not being satisfied in their lives as a person, [and for] certain cultures... to do what they used to do. That would bring stress. I think that's the number one problem for everyone. Always."

When participants were asked about major stressors for newcomers, language acquisition was identified as a requirement to secure employment, which implied its importance regarding financial security. In addition to this, Participant 9 explained that they observed that newcomers were motivated by the prospect of "integrat[ing] into the mainstream world and hav[ing] the confidence to use the vocabulary they need to meet their day-to-day goals". Participant 3 shared their experiences in the classroom, relaying a conversation she had had with one of her clients:

"I want to learn English, because English is life. I cannot do anything without English. Because when I go for shopping, I don't know, and when I go to the doctor, I don't know what to say. And then I have to always connect with my friend, just somebody who knows my language to help me out. And I don't like that, I want to be independent."

\section{Sense of Belonging}

The theme of newcomer's sense of independence was also articulated by the participants. This centered on the perception that the newcomer clients faced the challenge of having to let go of their sense of belonging and remake their identity. When prompted to discuss what they observed on a newcomer's sense of belonging, Participant 9 stated:

“...if you're a professional or you were successful in another country and you come [to Canada] and now you're learning the same skills that an elementary student is learning... nobody likes to feel intellectually deficient."

Other participants agreed, describing that newcomers "stopped fighting", "can't do what they used to", "feel like a stranger", "feel rejected", and "want to feel at home but they can't" (P2, P9, P1, P7, P11). Some participants mentioned that when clients confessed these feelings, there was also an apparent inability to recognize what else they needed to do to live here successfully. As such, staff felt obligated to guide them in getting the support they needed. To highlight this, Participant 1 shared that:

"some of them don't even have a clear expectation ... it's hard to say, generally speaking [for newcomers to admit], 'I need this one and that'. The general condition is that they don't know what they need".

Alongside conversations of service usage, accessibility was a pertinent stressor that five participants reported. Participant 6 observed that:

"It's already hard to access [services] because of the language [barrier]. They don't know what they need, but they don't know what the government can offer or what the community can offer, so the mere fact of knowing what they can use or what they can access is a stress for them."

On the other hand, Participant 5 reported that the problem connected with service usage is the "level of willingness to get the help" in relation to time commitments:

"Sometimes they are so busy, they say 'Teacher, that's a good idea, but I just can't do it. I work after school and come home late."” 


\section{Newcomer's Expectations}

Participants observed that the level of preparedness that newcomers had when coming to Canada was varied. Specifically, the desire to receive support and become successful remained, though participants indicated that newcomers ran into obstacles that are not easily resolvable. Additionally, there were many external factors that newcomers did not anticipate upon coming to Canada. Two participants reported that newcomers initially believed they were coming to "heaven" when coming to Canada (P2, P11). Participant 1 echoed this: "They [newcomers] are expecting to have someone hold their hands", specifically referring to front-line staff at this site. Other than concerns related to language and financial provisions, participants described stressors that took up their clients' time and energy: "attending class for financial support", "child care during class time", "the needs of [other] family members", "parents attending to their sick kids", "worrying about family back home", "navigating different agencies and services" and "feeling isolated" (P2, P10, P4, P3, P8, P9, P5). Consequently, as highlighted in seven transcripts, absenteeism was a common problem. Participants mentioned that clients work first to make ends meet, structuring their language learning classes around their work schedule. Participant 3 mentioned that:

\footnotetext{
"they're coming for the class they want to be, but they cannot concentrate [and] obviously they are tired... he was looking yellow... sliding down in the chair... he was here, but at times, he would just look into the space in front of him... a blank space".
}

Other participants reported concern that this behaviour seen in clients further impeded class participation and disrupted progression towards language learning and ultimately, successful integration.

\section{Front-Line Cultural Brokerage}

There was a strong sense of personal connection that the staff identified having with newcomer clients. Six participants who identified themselves as instructors reported they felt the need to build trusting relationships with their clients. Alongside the word "trust", "safe place" was a recurring term used by the participants revealing that they felt it their responsibility to create them. Participant 5 reported that:

"students are invited to share with their peers, stories or how they feel, and to really connect to build a community in this microcosm".

Participant 8 mentioned that they felt their job is "more than just teaching English", and that, "it's in your job description to identify and to be sensible, and to be empathetic". To add to this, Participant 3 identified that the classroom is "not only an opportunity to practice English, but an opportunity of expression", and other participants identified that clients connecting with peers was a strong promoter of client wellness. Front-line staff, particularly instructors, presented themselves as open and friendly and sought to accommodate their clients to the best of their ability. As such, they worked as cultural brokers by not only creating opportunities for English learning, but also assisting clients with settling into everyday life. Some participants reported facilitating with "bills", "finance support letter", "tutoring for [the clients'] kids", and "negotiating rent" (P5, P4, P9, P2). However, they came across situations in which they felt ill-equipped to help. Participant 8 described how they felt when a client disclosed that she left her son behind when coming to Canada:

"They [the clients] have such a big baggage with them, they come to the class and us teachers would like to do something to help them. But sometimes it's beyond you. Because there are so many areas where they need help, maybe they need help to overcome their grief, or deal with how they came as refugees here, or they don't like the food here or they don't like the climate here". 
It was apparent that the instructors' perception of the tribulations their clients faced as they endured day-to-day stresses tied into their desire to help their clients. In some cases, this was difficult as the problem extended beyond what can be achieved within the confines of the classroom.

\section{Discussion}

As per the literature existent on newcomer integration, when newcomers attempt to bridge their sense of belonging, it can become negative and stressful for newcomers to endure (Berry, 1997; Adkins, 1999; Wilkinson \& Garcea, 2017). As Berry et al. (1987) highlighted, cultural isolation and psychological distress are persistent and become obstacles in creating this sense of belonging. The fact that these problems in integration were reported in the literature over thirty years ago yet continue to exist today shows the need to address these longstanding problems to improve the quality of life of newcomers. This study sought to explore the experience of front-line workers in immigrant-serving languagelearning agencies, which in the existing literature has not been thoroughly explored in the context of the newcomer experience before. The findings of this study suggested that there is a need for cultural brokerage and language acquisition for newcomers. Front-line staff offered observations of factors that contributed to newcomer stress, and how these manifested in and outside the classroom. It was challenging for participants to identify what would make newcomers feel confident. The stories they shared highlighted unresolved tensions for each participant as they struggled to reconcile their personal and professional beliefs, perceptions and experiences.

It was the front-line workers' experiences and encounters with their newcomer clients that pointed to systemic issues and knowledge/skill gaps. This finding is similar prior literature citing obstacles including being underfunded, accountability for service gaps, and the struggle to create influence on the integration process (Simich et al., 2005; McIsaac, 2003). They have insights into what needed to be addressed within institutions that offer language support to newcomers. Feelings of sympathy, helplessness, and responsibility self-reported by participants enabled their drive to do as much as they can for their clients on top of their workload as a language-learning instructor. Even if they could not create successful outcomes in directly resolving their client's problems, they discussed their thought process, the consultations, and the repeated attempts at gaining support and resources on behalf of their clients. It was in these instances that they faced daily workplace challenges that were more emotional, abstract, and complex than their jobs presumed. To manage these extraordinary circumstances, they commonly drew upon their own experiences and assumptions about the work they needed to do to aid their individual clients' successful integration. For example, many participants voiced their belief that the ability to communicate well in English was essential to settling well. It was their interpretation of this that determined their assessment of what a client was experiencing, and what they thought a client needed. It is evident in the findings that their participation in action, was constantly changing on reflection of the daily interactions they had with newcomers. As workers identified the continual changes to their own knowledge, attitudes, and practices, a question not only for themselves but for understanding the extent of their roles at work was raised. Although this may have implications for boundaries, it was observed in the findings that this is also what allowed their personal relationships and rapport with their clients to flourish.

\section{Concluding Remarks}

This study considered the practice and values of the front-line staff working in agencies that served newcomers. This has not been widely focused on in the current literature. It was the staff members' interpretation of the newcomer experience that impacted the services in which they managed and made decisions in to attempt to create an even more successful sense of integration for newcomers. This ongoing shift in reflection to practice furthered the need to consider and assess the knowledge translation within the social systems in which newcomers are active. Moreover, this research shed light on the complexity of elements that are at play in language acquisition within newcomer services. By uncovering front-line workers' views regarding the current development of strategies, it may be possible to explore 
longer and shorter-term interventions that support the process of integration for both the service provider and the client. Finally, further research to explore the impact front-line workers and systems have on newcomers' successful integration is indicated.

\section{Acknowledgements}

We would like to acknowledge that this study was supported in funding by a Program for Undergraduate Research Experience (PURE) scholarship award from the University of Calgary, and Service Canada's Canada Summer Jobs Program.

\section{References}

Adkins, M., Birman, D., Sample, B., Brod, S., \& Silver, M. (1999). Cultural adjustment, mental health, and ESL: the refugee experience, the role of the teacher, and ESL activities. Spring Institute for International Studies.

Agrawal, S., \& Kurtz, N. (2019). Ethnic spatial segmentation in immigrant destination - edmonton and calgary. Journal of International Migration and Integration, 20(1), 199-222. https://doi.org/10.1007/s12134-018$\underline{0604-y}$

Audi, R. (2002). The sources of knowledge: In P. Moser (Ed.), The Oxford Handbook of Epistemology. (71-95). Oxford University Press Inc.

Bernard, H. R. (2011). Research methods in anthropology: Qualitative and quantitative approaches. Rowman \& Littlefield.

Berry, J., Kim, U., Minde, T., \& Mok, D. (1987). Comparative studies of acculturative stress. International Migration Review, 21(3), 491-511. https://doi.org/10.1177\%2F019791838702100303

Berry, J. (1997). Immigration, acculturation, and adaptation. Applied Psychology, 46(1), 5-34. https://doi.org/10.1111/j.1464-0597.1997.tb01087.x

Bowen, G. A. (2008). Naturalistic inquiry and the saturation concept: a research note. Qualitative Research, 8(1), 137-152. https://doi.org/10.1177/1468794107085301

Citizenship and Immigration Canada (2013). Welcome to Canada: what you should know. [Brochure] Cat. no. Ci460/1-2013E-PDF ISBN 978-1-100-21642-3 C\&I -1235-03-2013 Retrieved from https://www.canada.ca/en/immigration-refugees-citizenship/corporate/publications-manuals/publication-welcome-canadawhat-you-should-know.html

Edmonston, B. (2016). Canada's immigration trends and patterns. Canadian Studies in Population, 43(1),78-116. https://doi.org/10.25336/P64609

Elo, S., \& Kyngäs, H. (2008). The qualitative content analysis process. Journal of Advanced Nursing, 62(1), 107115. https://doi.org/10.1111/j.1365-2648.2007.04569.x 
Etikan, I., Musa, S.A., \& Alkassim, R.S. (2016). Comparison of Convenience Sampling and Purposive Sampling. American Journal of Theoretical and Applied Statistics, 5(1), 1-4. doi: 10.11648/j.ajtas.20160501.11

Finn, H. (2010). Overcoming barriers: adult refugee trauma survivors in a learning community. Teachers of English to Speakers of Other Languages Quarterly, 44(3), 586-596. doi:10.2307/27896747

Gardner, R. (1985). Social psychology and second language learning: The role of attitudes and motivation. Edward Arnold Publishers.

Government of Canada. (2011). Evaluation of the language instruction for newcomers to canada (LINC) program (Appendix A). [Report]. Retrieved from https://www.canada.ca/en/immigration-refugees-citizenship/corpo$\underline{\text { rate/reports-statistics/evaluations/language-instruction-newcomers-canada-2010/appendixa.html }}$

Government of Canada. (2017). WelcomeRefugees: key figures. [Report]. Retrieved from https://www.canada.ca/en/immigration-refugees-citizenship/services/refugees/welcome-syrian-refugees/key-figures.html

Government of Canada. (2018). Immigration, refugees and citizenship canada (IRCC) offices. [Website]. Retrieved from https://www.canada.ca/en/immigration-refugees-citizenship/corporate/contact-ircc/offices.html

Government of Canada. (2020). Find free newcomer services near you. [Website]. Retrieved from https://www.cic.gc.ca/english/newcomers/services/index.asp

Guo, Y. (2015). Language policies and programs for adult immigrants in canada: deconstructing discourses of integration. New Directions for Adult and Continuing Education, 2015(146), 41-51. https://doi.org/10.1002/ace.20130

Ho, L. (1998). Beyond the benchmarks: toward a view of adult ESL programming in a literacy framework. Alberta Journal of Educational Research, 44(2), 163.

Immigrant Services Calgary (2020). English as a second language (ESL): A directory of ESL programs and services for immigrants and international students in Calgary. [PDF]. Retrieved from https://www.immigrantservicescalgary.ca/our-services/english-testingeducation/english-testing-referral

Lincoln, Y., \& Guba, E. (1985). Naturalistic inquiry. Sage Publications.

McIsaac, E. (2003). Nation building through cities: A new deal for immigrant settlement in Canada. Caledon Institute of Social Policy.

Miles, M., Huberman, A., \& Saldana, J. (2014). Qualitative data analysis: A methods sourcebook. Sage Publications.

Simich, L., Beiser, M., Stewart, M., \& Mwakarimba, E. (2005). Providing social support for immigrants and refugees in canada: challenges and direction. Journal of Immigrant and Minority Health. 7(4), 259-268. doi:10.1007/s10903-005-5123-1

Smith, E. (2001). The role of tacit and explicit knowledge in the workplace. Journal of Knowledge Management, 5(4), 311-321. https://doi.org/10.1108/13673270110411733 
Statistics Canada. (2020). Estimates of the components of international migration, quarterly.

https://doi.org/10.25318/1710004001-eng

Strauss, A. \& Corbin, J. (1990). Basics of qualitative research: Grounded theory procedures and techniques. Newbury Park, CA: Sage Publications.

Wilkinson, L., \& Garcea, J. (2017). The economic integration of refugees in canada: A mixed record? Migration Policy Institute.

Yssaad, L., \& Fields, A. (2018). The canadian immigrant labour market: Recent trends from 2006 to 2017. [Report]. Statistics Canada, Labour Statistics Division. Retrieved from https://www150.statcan.gc.ca/n1/pub/71-606-x/71-606-x2018001-eng.htm 